\title{
Assessment of Household Waste Management and Hygienic Practice in Yirgalem Town, Dale Woreda, Sidama Zone, South Nation Nationalities and Peoples of Region, Ethiopia
}

\author{
Belachew Tekleyohannes \\ Department of Environmental Health, Debre Birhan Health Science College, Debre Birhan, Ethiopia
}

Email address:

tekleyohannes@gmail.com

\section{To cite this article:}

Belachew Tekleyohannes. Assessment of Household Waste Management and Hygienic Practice in Yirgalem Town, Dale Woreda, Sidama Zone, South Nation Nationalities and Peoples of Region, Ethiopia. Journal of Health and Environmental Research.

Vol. 5, No. 2, 2019, pp. 41-49. doi: 10.11648/j.jher.20190502.12

Received: March 30, 2019; Accepted: May 30, 2019; Published: June 12, 2019

\begin{abstract}
Currently rapid rate of urbanization and the increasing income of people leads to the generation of high quantities of waste. This makes final disposal of waste difficult. Since urbanization is faster in developing and migrate peoples to a new, modern way of life, an improved level of awareness, new skill and a learning process, the problem is more acute in developing countries. This study aims is to assess household waste management and hygienic practice. Community based cross sectional study was employed to assess the household waste management and hygienic practice among residents of Kidist mariam kebele of Yirgalem town. A total of 316 households were selected from 1, 115 households using systematic random sampling. Data was collected through interview and observation. The study discovered that majority of the households, (36\%) disposed solid wastes through municipality and $95.7 \%$ of households had temporary storage means for solid waste. About $94.3 \%$ of the respondents revealed that the responsibility of waste management is left for women and girls. $83.7 \%$ of households had latrines and almost majority were simple traditional pits latrine. From those households with latrine the habit of hand-washing after defecation was reported to be about $64.3 \%$. This study revealed that household management of waste in the community of Yirgalem town is poor in terms of their liquid waste management. More than seventy five percent of households flush away their waste water indiscriminately. But it is moderately good in terms of their solid waste management. The habit of hand washing after defecation is significantly associated with the educational status of the respondents $(\mathrm{P}<0.05)$. Recommendation has been given to municipality to improve the waste management system of the town.
\end{abstract}

Keywords: Waste, Solid Waste, Liquid Waste, Waste Disposal, Waste Management, Hygienic Practice

\section{Introduction}

Waste can be defined as unwanted materials that is discarded or left as unwanted. These materials are in general considered as byproducts of human activities that are resulted from preparation, manufacture, construction, packing, and renovation of structures and also from mining operations. Everything in the "waste stream" has residual value for someone or some business in the community. Waste represents valuable resources as ground cover to reduce erosion, fertilizer to nourish the crops, the source of energy etc. [1]
Currently rapid rate of urbanization and the increasing income of people leads to the generation of high quantities of waste. This makes final disposal of waste difficult. Since urbanization is faster in developing and migrate peoples to a new, modern way of life, an improved level of awareness, new skill and a learning process, the problem is more acute in developing countries.

However, when the rate of urbanization gets out of control, it poses a big challenge to governance so that optimizing forces become weakened, institutional capabilities become 
inadequate and ineffective, and with these, the problems of urbanization are compounded. [2]

The term waste management is defined as the process of collecting, transporting, processing or disposing, managing and monitoring of waste materials. It usually relates to materials produced by human activity and the process is generally undertaken to reduce their effect on health, the environment or aesthetics. The major focus of this research is on waste management practices as obtains in the urban developing nations. Waste includes all items that people no longer have any use for, which they either intend to get rid of or have already discarded and these include: packing items garden waste, old paints containers, vegetables, metals etc. [3]

Improper waste management has been a major problem to environmental, economic and human health and existence, affecting both rural and urban areas. Water, soil and air pollution have been attributed to an ecological phenomena. A clean environment enhance good health and good health further increase the productivity of man. Therefore, it can be said that a good and clean environment invariably affects the wealth and economic status of the nation. [4]

Globally, 2.6 billion people or 39 percent of the world population do not use improved sanitation. Some 1.1 billion people still defecate in the open air. Ten countries, including Ethiopia are home to 81 per cent of them. Open defecation is largely a rural phenomenon, most widely practiced in Southern Asian and Sub-Saharan Africa. At current rates of progress the world will miss the MDG sanitation target by almost 1 billion people. The magnitude of the hygiene challenge also remains overwhelming. [5]

Study conducted by Environmental Protection Authority (EPA) and World Bank in 2004 showed that per capita amount of waste generated in Ethiopia ranged from 0.17 to $0.48 \mathrm{~kg} / \mathrm{person} /$ day for urban areas to about 0.11 to 0.35 $\mathrm{kg} / \mathrm{capita} /$ day for rural areas. The range depends on several factors such as income and season. The total generation of municipal solid waste in Ethiopia in 2003 is estimated to be 2.8 to 8.8 million tones. This can be split to approximately 0.6 to 1.8 million tons from rural areas and 2.2 to 7 million tons from urban areas. [6]

Disposal is the final method of waste management including: land filling: which involves burying the waste in abandoned or unused quarries, mining voids or burrow pits and covering it with layers of soil; incineration: involves subjection of solid organic wastes to combustion at a very high temperature so as to convert them into residue or gaseous products; Composting: this is an aerobic, biological process of degradation of biodegradable organic matter; hog feeding: this involves feeding animals like pigs with left over materials of waste; mechanical destructor: this involves the use of machines to destroy waste materials. [7]

The management of waste should focus on how to find the value and redirect it back to the community. Unfortunately, our collecting and dumping process mix and crush everything together; and make separation an expensive and sometimes impossible task to properly manage wastes. [8]

\section{Methodology}

\subsection{Study Design}

A community based cross sectional study was conducted from to assess the household waste management and hygienic practice among community of Yirgalem town, Dale woreda, Sidama zone, SNNPR, Ethiopia.

\subsection{Study Area and Period}

The study was conducted in, Yirgalem town, Dale woreda, Sidama zone, SNNPR, Ethiopia. Yirgalem is one of the 22 reform towns found in southern region, which was established in 1924 E.C by Ras Desta Damtew. It is found 47 kms from Hawassa, which is the capital city of the SNNPR and sidama zone and $311 \mathrm{~km}$ south of Addis Ababa, capital of the country. Its absolute location is $6^{\circ} 45^{\prime} \mathrm{N} \& 38^{\circ} 25^{\prime} \mathrm{E}$ longitude and $6.75^{\circ} \mathrm{N} \& 38.417^{\circ} \mathrm{E}$ latitude. It is the largest settlement in Dale woreda. The town is bordered by tuba, kegane and keshoy in the north, Awada and mesincho in the South, Wansho woreda in the East and hida, kalite and wanenata in the west. It has a total area of 1140 hectares. It is located 1790 meters above sea level. The general climatic condition of the town is midland (woyna dega).

Yirgalem has 2 sub cities namely filwuha and arada. There are 3 kebeles within each sub cities. Filwuha sub city contains mehal-ketema, Awada stadium and aposto kebeles. Arada subcity contains woha limat, kidist-mariam and mesincho-mewchakebeles.

Yirgalem town lies on the main road which passes through Aposto and has many tourist attraction sites. It is a home of a lodge (known as Aregash Lodge) which is built at the out skirt of the town. There is also Gidabo hot springs bath which is located $41 \mathrm{~km}$ far south of Hawassa town which is believed to cure many diseases and also used as leisure for the surrounding people and other towns. In addition, there is also a hot spring bath in Aposto (Fil-wuha sub-city).

\subsection{Inclusion and Exclusion Criteria}

\subsubsection{Inclusion Criteria}

All households whose residence is found in the sampling zone and who accepted to participate were included in this study.

\subsubsection{Exclusion Criteria}

Those who are not our sampled households, who disagreed to participate in the study and those whose houses were closed during data collection were excluded from this study.

\subsection{Sampling Technique}

After selection of Kidist mariam kebele from the six kebeles in the town by lottery method, the area were mapped and then zoned to know how wide the area is and where to start the study. The Kebele will be classified in to 4 zones and 1, 115 houses will be numbered. Systematic random sampling will be used to select 316 residential houses out of 1,115 houses using population proportion formula. 


\subsection{Data Collection Technique}

Data was collected using structured questionnaire from 316 household. We also assess the practice of the study community towards waste management and hygienic practice through observation.

\subsection{Data Process, Presentation and Analysis}

All the collected data was checked and analyzed using software known as SPSS version 16. Tables and figures were used for the presentation of the study result and the interpretation of the study was carry out by relating the finding in the town with the other conducted researches in related subjects.

\subsection{Data Quality Assurance}

In order to obtain quality data, data collectors (we) applied our theoretical knowledge that we have obtained through our stay in the campus on how to collect data uniformly and to avoid misunderstanding that may arise with unfamiliar terminologies. Standardized questionnaires were prepared in collaboration with our advisor and applied for this research. The quality of the data was also assessed by investigators and cross checking of completed questionnaire was performed for consistency and completeness of data. Finally 300 questionnaires were filled and 16 participants disagreed to participate in the interview; this makes the non-response rate to be $5.1 \%$ and all the other 300 questionnaires were fully filled.

\subsection{Ethical Consideration}

Official letter was obtained from Hawassa University, CBE office to Yirgalem town municipality and the respective offices. Kebele administrations and the respective study households have been consulted so as to get an informed consent for the actual data collection. Respondents of the households were assured about the confidentiality of the information obtained and the right of the respondents to differ from being interviewed will be respected as well.

\section{Results}

\subsection{Socio- Demographic Characteristics}

Data was collected from 300 households. Only residents who were household heads were invited to participate in the study. Out of the 300 respondents, $110(36.7 \%)$ of them were males, and $190(63.3 \%)$ of them were females. Out of which 213 (71\%) were married, 43 (14.3\%) were single, 23 (7.7\%) were widowed and $21(7 \%)$ were divorced. High proportion of the participants were government employees and merchants, 89 (29.7\%) and 88 (29.3\%), respectively. The majority of our respondents earn monthly income of both between 501-1000 (29.7\%) and 1001-2000 (29.7\%) Ethiopian Birr. Of our respondents majorities are Protestant $151(50.3 \%)$ and Orthodox $101(33.7 \%)$ religions followers. From our respondents $94(31.3 \%)$ educated up to grade 12 and above while $26(8.7 \%)$ had no formal education and cannot read and write. (Table 1)

Table 1. Socio-demographic data of the respondents in Yirgalem town, Dale woreda, kidist mariam kebele, SNNPR, Ethiopia, 2017.

\begin{tabular}{|c|c|c|c|}
\hline Demographic variables & Male n (\%) & Female n (\%) & Total n (\%) \\
\hline Gender & $110(36.7)$ & $190(63.3)$ & $300(100)$ \\
\hline \multicolumn{4}{|l|}{ Marital status } \\
\hline Married & $90(30)$ & $123(41)$ & $213(71)$ \\
\hline Single & $7(2.3)$ & $36(12)$ & $43(14.3)$ \\
\hline Widowed & $8(2.7)$ & $15(5)$ & $23(7.7)$ \\
\hline Divorced & $5(1.7)$ & $16(5.3)$ & $21(7)$ \\
\hline \multicolumn{4}{|l|}{ Educational status } \\
\hline Illiterate & $10(3.3)$ & $16(5.4)$ & $26(8.7)$ \\
\hline Read and write & $17(5.7)$ & $31(10.3)$ & $48(16)$ \\
\hline $1-6$ & $10(3.3)$ & $18(6)$ & $28(9.3)$ \\
\hline $7-12$ & $46(15.3)$ & $58(19.4)$ & $104(34.7)$ \\
\hline grade 12 and above & $41(13.7)$ & $53(17.6)$ & $94(31.3)$ \\
\hline \multicolumn{4}{|l|}{ Religion } \\
\hline Orthodox & $47(15.7)$ & $54(18)$ & $101(33.7)$ \\
\hline Muslim & $13(4.3)$ & $10(3.4)$ & $23(7.7)$ \\
\hline Protestant & $68(22.7)$ & $83(27.6)$ & $151(50.3)$ \\
\hline Catholic & $7(2.3)$ & $6(2)$ & $13(4.3)$ \\
\hline Other & $5(1.7)$ & $7(2.3)$ & $12(4)$ \\
\hline \multicolumn{4}{|l|}{ Occupation } \\
\hline Government employee & $55(18.3)$ & $40(11.4)$ & $89(29.7)$ \\
\hline Merchant & $29(9.6)$ & $59(19.7)$ & $88(29.3)$ \\
\hline Student & $20(6.7)$ & $11(3.6)$ & $31(10.3)$ \\
\hline house wife & & $26(8.7)$ & $26(8.7)$ \\
\hline Solider & $8(2.7)$ & & $8(2.7)$ \\
\hline Carpenter & $1(0.3)$ & & $1(0.3)$ \\
\hline Farmer & $43(14.3)$ & $14(4.6)$ & 57 (19) \\
\hline \multicolumn{4}{|l|}{ Monthly income } \\
\hline$<500$ & $35(11.7)$ & $19(6.3)$ & $54(18)$ \\
\hline $501-1000$ & $61(20.4)$ & $28(9.3)$ & 89 (29.7) \\
\hline $1001-2000$ & $56(18.7)$ & $33(11)$ & $89(29.7)$ \\
\hline$>2000$ & $37(12.4)$ & $31(10.3)$ & $68(22.7)$ \\
\hline
\end{tabular}

\subsection{Solid Waste Management Practice}

The research further sought to find out which person in the family deals with household waste. Results show that other women in the family and mothers deal with household waste with frequency of $110 \quad(36.7 \%)$ and $101 \quad(33.6 \%)$, respectively. (Table 2)

Table 2. shows the responsibility for solid waste management at household level in Yirgalem town, Dale woreda, kidist mariam kebele, SNNPR, Ethiopia, 2017.

\begin{tabular}{lll}
\hline Responsible Person & Frequency & Percent \\
\hline Mother & 101 & 33.6 \\
Other women in the family & 110 & 36.7 \\
Children female & 72 & 24.0 \\
Children male & 10 & 3.3 \\
Father & 7 & 2.3 \\
Total & 300 & 100.0 \\
\hline
\end{tabular}

\subsection{Methods Used to Dispose Waste}

Different methods are used to dispose the waste which is released from the households. Of respondents, relatively large proportion, 107 (36\%) use municipality service to dispose their wastes. Significant number of respondents also used open dump outside yard, i.e. 80 (27\%). Other significant proportion also practiced refuse disposal pit 55 (18\%). (Figure 1) 


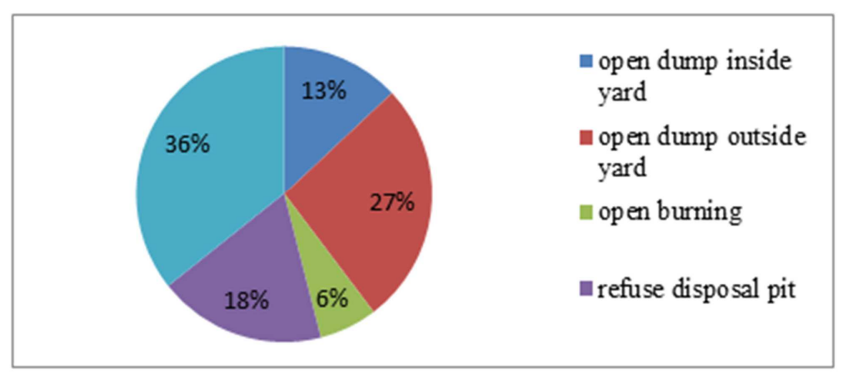

Figure 1. Show methods used by households to dispose their waste in Yirgalem town, Dale woreda, kidist mariam kebele, SNNPR, Ethiopia, 2017.

From those respondents who responded that they use open dump outside yard method of disposal 41 (13.7\%) dispose their wastes early in the morning, $26(8.7 \%)$ dispose during the night time while $8(2.7 \%)$ of respondents dispose at day time. (Table 3)

Table 3. Show the time taken by households for open disposal outside the yard by the households in Yirgalem town, Dale woreda, kidist mariam kebele, SNNPR, Ethiopia, 2017.

\begin{tabular}{lll}
\hline $\begin{array}{l}\text { Time taken for open disposal outside yard of } \\
\text { waste }\end{array}$ & Frequency & Percent \\
\hline Early in the morning & 41 & 13.7 \\
At day time & 8 & 2.7 \\
During night time & 25 & 8.3 \\
At any time & 6 & 2 \\
Total & 80 & 27 \\
\hline
\end{tabular}

The research also assessed that whether the respondents burn their solid waste or not. Significant number of respondents $182(61 \%)$ answered yes but the remaining 118 (39\%) answered no. From those who burn solid waste 134 $(44.7 \%)$ burn inorganic plastics, while the remaining 48 (16\%) burn organic dry wastes. From those who burn solid waste high proportion $139(46.3 \%)$ have no properly arranged place for waste burning, while only 43 (14.3\%) have arranged place for waste burning. (Table 4)

Table 4. shows whether the households arranged a place for waste burning or not in Yirgalem town, Dale woreda, kidist mariam kebele, SNNPR, Ethiopia, 2017.

\begin{tabular}{lll}
\hline Presence of place for burning of waste & Frequency & Percent \\
\hline Yes & 43 & 14.3 \\
No & 139 & 46.3 \\
Total & 182 & 61 \\
\hline
\end{tabular}

Table 5. Show solid waste management of household in Yirgalem town, Dale woreda, kidist mariam kebele, SNNPR, Ethiopia, 2017.

\begin{tabular}{llll}
\hline Variable & & Frequency & Percentage \\
\hline \multirow{3}{*}{ Cleaning of household compound } & Yes & 284 & 94.7 \\
& No & 16 & 5.3 \\
& Total & 300 & 100 \\
Presence of temporary waste storage & Yes & 287 & 95.7 \\
means & No & 13 & 4.3 \\
& Total & 300 & 100 \\
Cover of waste storage means & Yes & 95 & 31.7 \\
& No & 205 & 68.3 \\
Onsite separation of waste before & Yotal & 300 & 100 \\
\hline
\end{tabular}

\begin{tabular}{llll}
\hline Variable & & Frequency & Percentage \\
\hline storage & No & 228 & 76 \\
& Total & 300 & 100 \\
Washing of hands after & Yes & 284 & 94.7 \\
collection/disposal of solid waste & No & 16 & 5.3 \\
& Total & 300 & 100 \\
\hline
\end{tabular}

Of respondents a very high proportion, $284(94.7 \%)$ clean their houses every day. But only a small proportion $16(5.3 \%)$ of respondents clean their houses often. The larger proportion of the respondents have temporary storage at home 287 $(95.7 \%)$, the remaining $13(4.3 \%)$ do not have designated temporary storage. Out of those who have temporary storage at home, the research also sought out from what materials those containers made of. With this respect, respondents who use sack as temporary storage have the largest proportion, $128(42.7 \%)$, significant proportion of the respondents also use plastic dust bins as temporary waste storage 76 (25.3\%) and the largest proportion of waste storage used by households do not have cover $205(68.3 \%)$ and the rest 95 (31.7\%) have cover. (Figure 2)

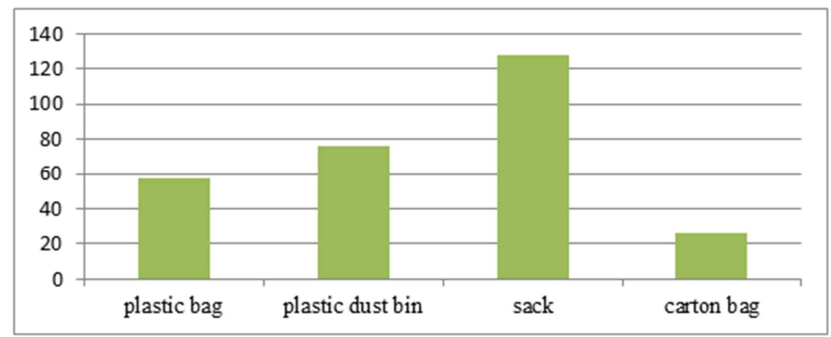

Figure 2. Type of container used by households for temporary storage of waste in Yirgalem town, Dale woreda, kidist mariam kebele, SNNPR, Ethiopia, 2017.

Again of the respondent $72(24 \%)$ of households apply onsite separation of waste before storage and $228(76 \%)$ of households do not apply onsite separation of waste before storage.

Majority of the respondents $284(94.7 \%)$ have the habit of hand washing after collection/disposal of solid waste and some households $16(5.3 \%)$ do not have the habit of hand washing after collection/disposal of solid waste.

Table 6. Show the type of cleaning agent used by respondents to wash their hands after collection/disposal of waste in Yirgalem town, Dale woreda, kidist mariam kebele, SNNPR, Ethiopia, 2017.

\begin{tabular}{lll}
\hline Type of cleaning agent used to wash hands & Frequency & Percentage \\
\hline Water only & 87 & 29 \\
Water and soap/ash & 187 & 62.3 \\
Water and other cleaning agent & 26 & 8.7 \\
Total & 300 & 100 \\
\hline
\end{tabular}

From the total respondents $231(77 \%)$ do not have any personal protective equipment during collection/disposal of waste and small number of respondents 69 (23\%) have personal protective equipment during the collection/disposal of waste and finally wash hand with soap and other cleaning agent which is shown in the table below. 
Table 7. shows respondents that can use personal protective equipment during collection/disposal of waste in Yirgalem town, Dale woreda, kidist mariam kebele, SNNPR, Ethiopia, 2017.

\begin{tabular}{lll}
\hline $\begin{array}{l}\text { Respondents that use personal protective } \\
\text { equipment }\end{array}$ & Frequency & Percentage \\
\hline Yes & 69 & 23 \\
No & 231 & 77 \\
Total & 300 & 100 \\
\hline
\end{tabular}

From a total of 300 households assessed for presence of excreta disposal systems, $283(94.3 \%)$ reported that they have latrine; while 17 (5.7\%) were without latrine. From those households who had latrine, 251 (83.7\%) were traditional pit latrines, and $268(89.3 \%)$ were owned privately. Again from those households who had latrine, 49 $(16.3 \%)$ were VIP latrine, and $32(10.7 \%)$ were owned share. Presence of flies was observed in $136(45.3 \%)$ of the households. The finding of this study also revealed that 227 (75.7\%) households did not have appropriate wastewater disposal systems and; hence they simply flushed the waste water in or around their compounds (Table 8). Out of the total respondents $283(94.3 \%)$ who indicated the availability of latrine; $196(69.3 \%)$ had hand washing facilities near the latrine and the remaining $87(30.7 \%)$ had no hand washing facility near the latrine. However, it was $182(64.3 \%)$ of the respondents from households with latrines reported washing their hands after defecation and the rest 101 (35.7\%) had no habit of washing hand after defecation. From these that wash hands after defecation, $133(73.1 \%)$ expressed to use soap and water and $49(26.9 \%)$ reported that they use water only to wash their hands.

Table 8. Show liquid waste management at household level in Yirgalem town, Dale woreda, SNNPR, Ethiopia, 2017.

\begin{tabular}{|c|c|c|c|}
\hline Variable & & Frequency & Percentage \\
\hline \multirow{3}{*}{$\begin{array}{l}\text { Presence of appropriate } \\
\text { waste water disposal system }\end{array}$} & Yes & 73 & 24.3 \\
\hline & No & 227 & 75.7 \\
\hline & Total & 300 & 100 \\
\hline \multirow{3}{*}{ Availability of latrine } & Yes & 283 & 94.3 \\
\hline & No & 17 & 5.7 \\
\hline & Total & 300 & 100 \\
\hline \multirow{3}{*}{ Type of latrine } & $\begin{array}{l}\text { Traditional } \\
\text { pit latrine }\end{array}$ & 251 & 83.7 \\
\hline & VIP latrine & 49 & 16.3 \\
\hline & Total & 300 & 100 \\
\hline \multirow{3}{*}{ Owner ship of latrine } & Private & 268 & 89.3 \\
\hline & Shared & 32 & 10.7 \\
\hline & Total & 300 & 100 \\
\hline \multirow{3}{*}{$\begin{array}{l}\text { Presence of flies in and } \\
\text { around the latrine }\end{array}$} & Yes & 136 & 45.3 \\
\hline & No & 164 & 54.7 \\
\hline & Total & 300 & 100 \\
\hline \multirow{3}{*}{$\begin{array}{l}\text { Households with washing } \\
\text { facility near to the latrine }\end{array}$} & Yes & 196 & 69.3 \\
\hline & No & 87 & 30.7 \\
\hline & Total & 283 & 100 \\
\hline \multirow{3}{*}{$\begin{array}{l}\text { Households that wash hands } \\
\text { after defecation }\end{array}$} & Yes & 182 & 64.3 \\
\hline & No & 101 & 35.7 \\
\hline & Total & 300 & 100 \\
\hline
\end{tabular}

The research also assessed weather the respondents store solid waste separate or mixed. The larger proportion of the participants responded that they don't care for waste separation, $217(72.3 \%)$. But only a little proportion of the respondents practiced to separate their solid waste, 83 (27.7\%). (Table 9)

Table 9. Shows whether households separate or mix waste before storage in Yirgalem town, Dale woreda, kidist mariam kebele, SNNPR, Ethiopia, 2017.

\begin{tabular}{lll}
\hline Households that store mixed waste & Frequency & Percentage \\
\hline Yes & 217 & 72.3 \\
No & 83 & 27.7 \\
Total & 300 & 100 \\
\hline
\end{tabular}

To the question asked for how long they store their waste, significant proportion of respondents store their waste for $<3$ days and 3-6 days in the temporary storage before hauling to the final disposal, 109 (36.3\%) and 77 (25.7\%), respectively. (Figure 3)

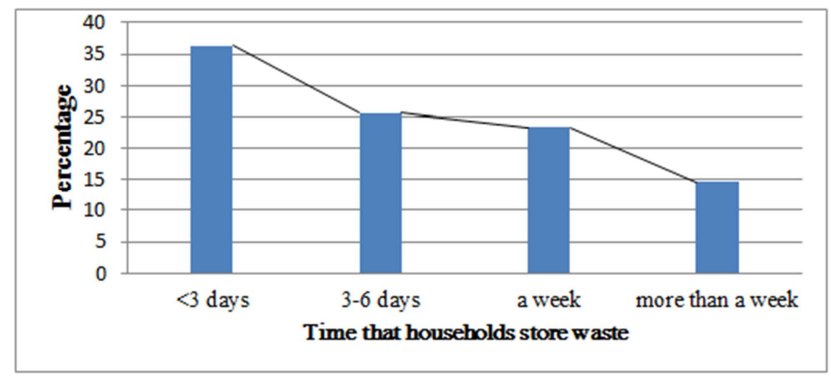

Figure 3. Show the time that waste is stored at household level in Yirgalem town, Dale woreda, kidist mariam kebele, SNNPR, Ethiopia, 2017.

The research also assessed to find the major constituents of the household wastes. The major proportion of the wastes produced from the households is dominated by organic vegetable $156(52 \%)$ and followed by paper which 88 $(29.3 \%)$ of participants responded. (Figure 4 )

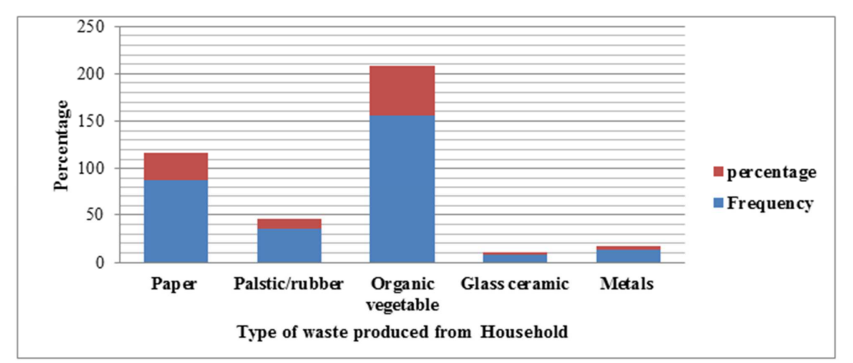

Figure 4. Show the main type of waste produced by households in Yirgalem town, Dale woreda, kidist mariam kebele, SNNPR, Ethiopia, 2017.

The research assessed whether the households use solid waste for other purpose or not. To this regard high proportion of the respondents, $166(55.3 \%)$ do not use solid waste for other purpose, but $134(44.7 \%)$ use solid waste for other purpose. Out of those who use solid waste for other purpose, significant number of respondents uses it for cattle feeding, $61(20.3 \%)$ and fuel $55(18.3 \%)$. (Figure 5) 


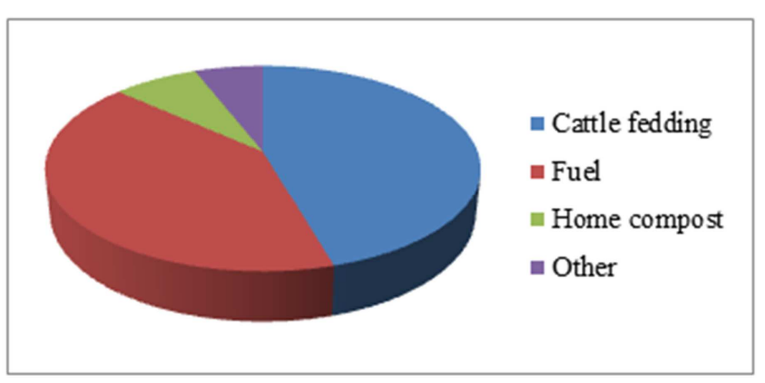

Figure 5. Households that can use waste for other purpose in Yirgalem town, Dale woreda, kidist mariam kebele, SNNPR, Ethiopia, 2017.

The respondents were asked whether they sell wastes or not; $203(67.7 \%)$ are found to sell waste while the remaining $97(32.3 \%)$ don't sell wastes. From those who sell wastes $69(23 \%)$ sell shoes, $63(21 \%)$ sell plastics, 41 $(13.7 \%)$ sell metals and glasses and $30(10 \%)$ sell cloths. The research also assessed to whom they sell wastes; out of those who sell wastes, $156(52 \%)$ sell to Koralios', 48 (16\%) sell to 'Liwach', while the remaining 4 (1.3\%) sell to others like to those who locally recycle wastes. The research also assessed whether they reuse household wastes or not. The majority of the respondents 260 (86.7\%) responded that they don't reuse household wastes. only 40 $(13.3 \%)$ reuse their wastes. from those who reuse household waste, the majority reuse plastics and glasses, 39 (12.1\%) and $38(11.8 \%)$ respectively. (Figure 6 )

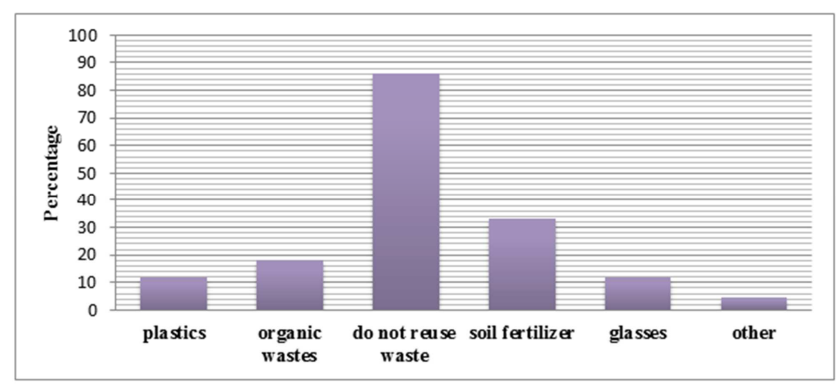

Figure 6. shows whether households reuse waste or not in Yirgalem town, Dale woreda, kidist mariam kebele, SNNPR, Ethiopia, 2017.

The respondents also asked what means they use to transport waste. High proportion of the respondents 125 $(41.7 \%)$ use donkey driven carts, significant number of respondents used by hands or ourselves 102 (34\%). 73 $(24.3 \%)$ of the respondents dispose by using hand pushed carts. (Figure 7)

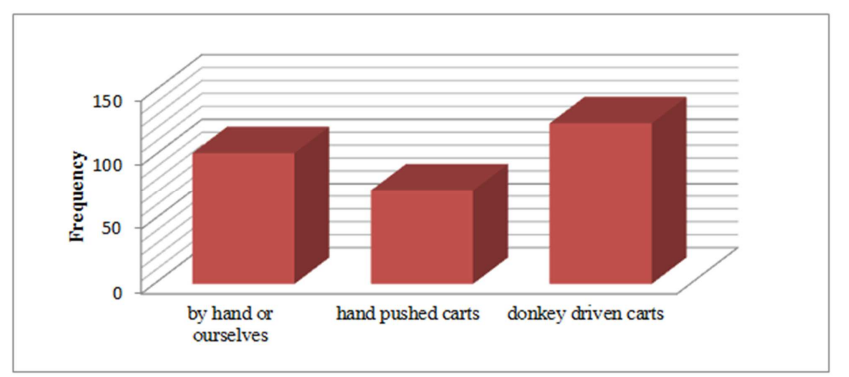

Figure 7. Shows means of waste transportation used by households in Yirgalem town, Dale woreda, kidist mariam kebele, SNNPR, Ethiopia, 2017.
The research also assessed whether the respondents know if there is anybody that monitors waste collection and disposal. The majority of them know that there is somebody who monitors waste collection and disposal, 207 (69\%) but the remaining $93(31 \%)$ do not know the presence of monitoring body. Out of those who know the presence of somebody who monitors solid waste disposal, they were asked what measures are taken on those who dispose waste improperly. $127(42.3 \%)$ said that verbal warning is taken on them, $83(27.7 \%)$ said coercion is taken on them to clean by themselves. (Figure 8)

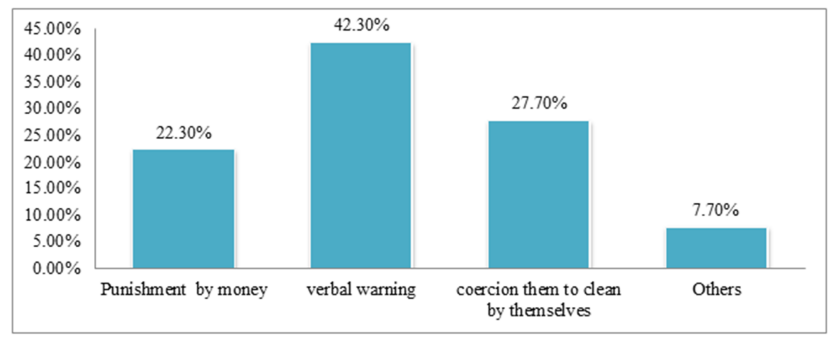

Figure 8. Shows types of action taken on those who dispose waste improperly in Yirgalem town, Dale woreda, kidist mariam kebele, SNNPR, Ethiopia, 2017.

Out of the total respondents $283(94.3 \%)$ who indicated the availability of latrine; $196(69.3 \%)$ had hand washing facilities near the latrine and the remaining 87 (30.7\%) had no hand washing facility near the latrine. However, it was $182(64.3 \%)$ of the respondents from households with latrines reported washing their hands after defecation and the rest $101(35.7 \%)$ had no habit of washing hand after defecation. From these that wash hands after defecation, 133 (73.1\%) expressed to use soap and water and 49 (26.9\%) reported that they use water only to wash their hands.

\section{Discussion}

The study revealed that in most of the households, $94.3 \%$ waste management was the responsibility of women (girls and mothers), which matches with the research by Bizatu and Nega in Kersa woreda, eastern Ethiopia, 2010; which was $87.9 \%$. Men (father and boys) were reported to manage waste only in $5.7 \%$ of the households, which is again in matches with Kersa woreda, eastern Ethiopia which was 1.6\%. [9]

The response presents evidence that there is gender imbalance in relation to family member's responsibility for waste management and so that women and girls shouldering the greatest burden. Provision of adequate sanitation facilities is not only a socioeconomic and developmental issue but also an issue of self-respect, human dignity and public health. [10]

The basic functional units of solid waste management start with onsite storage and handling of wastes. This study indicated that $287(95.7 \%)$ had temporary storage for the generated solid waste. Moreover from those households which had temporary storage only $95(31.7 \%)$ were found to have cover at the time of data collection. This indicates that 
the stored wastes were exposed to insects and rodents. The vast majority of the respondents, 284 (94.7\%) reported that they clean their home and compound regularly. Also all of those $284(94.7 \%)$ reported that they wash their hands after handling solid wastes. These two practices need to be encouraged and enhanced. Many researchers have underlined the relationship between public health and improper solid waste management. [11]

This study indicated that majority of the households dispose solid wastes through municipality after they collect in a temporary storage and the other major households dispose their waste in open dump outside yard, open pit or by open burning. This leads to a polluted environment. This finding is similar with a survey of SNNPR, Ethiopia (2000), where majority, $(67 \%$,) of the households dispose waste in open fields. Again this finding is not different from a similar study conducted in Haramaya Woreda in 2003, where it was reported that open disposal of refuse and feces was practiced in about $93.4 \%$ of the households. [12]

From our respondents, relatively large proportion, 36\% use municipality service to dispose their wastes and this method of disposing creates a good opportunity to use such waste for other purpose if municipality gives attention. Which this method is not used by households of Kersa woreda as the research by Bizatu and Nega, 2010, shows. This result is also quit higher than that found in Mogadishu, Somalia where only $15 \%$ of the respondents use municipal waste collection service. [13]. This is appreciable and promotable practice where the sanitation of the town will be kept safe, provided that the final disposal site is well protected. From our respondents $13 \%$ dispose waste in open disposal inside the yard, this is lower than that of the research done by Bizatu and Nega (2010) at Kersa woreda eastern Ethiopia which is $38.5 \%$. $27 \%$ of our respondents practiced open disposal outside the yard which is also lower than the same finding from Kersa woreda, eastern Ethiopia, which was $28.1 \%$ of households practice open dump outside yard. $18 \%$ of the respondents used refuse disposal pits, which has a high gap from the finding at Kersa woreda, eastern Ethiopia, by Bizatu and Nega, 2010 in which 26.5\% households used refuse disposal pit for the same disposal practice. But only $33.3 \%$ of respondents practiced using solid waste as manure, where there is gap from the finding at Kersa woreda, eastern Ethiopia, which is reported to be $85.6 \%$ of households used solid waste for manure as done by Bizatu and Nega, 2010.

High proportion of respondents in this study cleans their houses regularly (94.7\%) which is closer to with the research by Bizatu and Nega in Kersa woreda, eastern Ethiopia (2010) which was $88.2 \%$. regarding temporary storage for generated refuse at home the larger proportion $95.7 \%$ of households have a temporary storage. This was much higher than and in a good condition related to the finding by Bizatu and Nega, in Kersa woreda, eastern Ethiopia (2010) which was only $6.9 \%$ of households have a temporary storage for waste. From respondents the highest proportion use sacks as temporary storage, $42.7 \%$, which is quit comparable and higher than Mohammed in Asendabo town in 2002, which was $39.5 \%$. Those who use plastic dust bin also hold significant number, $25.3 \%$ again which is higher than the one done in Asendabo town by Mohammed in 2002, where the respondents who use the same storage type were $15.8 \%$. To this regard the practice of the respondents is appreciable, because related to other findings in other area higher number of respondents us temporary storage. Using temporary storage is helpful during loading in order to keep the surrounding clean. [14]

Hand-washing with soap is a cost effective intervention not only against diarrheal diseases but also for the prevention of acute respiratory infections. [15] Diarrhea episodes are reduced: $36 \%$ by improving sanitation and $48 \%$ through hand washing with soap. [16] The majority 284 (94.7\%) of the respondents in the current study claimed that they wash their hands regularly after touching of solid wastes. But, it is only $187(62.3 \%)$ of them reported the use of soap or ash to clean their hands.

In communities where the usage of latrine is low the prevalence of water borne diseases, especially diarrhea, is found to be very high. [17]

The present study revealed that $283(94.3 \%)$ of the surveyed households had access to latrine. From those households who had latrine; most, 251 (83.7\%), use traditional pit latrines which could create conducive environment for flies to breed unless proper cover is used for the hole and kept clean. In this study, human feces were also observed on the floor and wall of many of the latrines and inside the compound. This could cause enteric communicable diseases which affect the inhabitants and the community at large. The presence of hand washing facilities near the latrines encourages the users to wash their hands after toilet use. This study showed $196(65.3 \%)$ of the households having latrines had hand-washing facilities near the latrines. Washing of hand with soap after visiting toilet (or after defecation) has a paramount importance in decreasing of diarrheal and other parasitic diseases. [18] The study revealed that $145(48.3 \%)$ of the households with latrines wash their hands after defecation and majority of respondents $187(62.3 \%)$ use both water and soap/ash to wash their hands which is an effective means to remove the filth and pathogenic microorganisms. This is significantly associated with the educational status of the households. The rest of the households did not have any fixed place for defecation.

The research also sought to find out the main types of wastes produced in the households. Result indicated that there are different types of wastes produced by households. Organic vegetable and Paper waste is the most common type of waste which is produced from households which is $52 \%$ and $29.3 \%$ respectively. This result is lower than with the result that is done in Mogadishu city which is $73 \%$ of organic vegetable waste is produced. [13]. This indicates that the waste produced in the town can be a good raw material for reuse and other organic fertilizer production. The research also sought out whether the households reuse waste or not. In this regard high proportion of respondents $(55.3 \%)$ doesn't use solid waste for other purpose. This could be one of the 
reasons for increased amount of solid waste hauled to disposal sites each time. However, the remaining $44.7 \%$ use solid waste for other purposes. Out of these, significant number uses it for cattle feeding (20.3\%). 18.3\% also used it for fuel, however, using bio fuel at home is not supportable that it is the main source of indoor air pollution and home compost which shall be promoted. Moreover respondents were asked whether they sell wastes or not. $67.7 \%$ are found to sell wastes this is highly contributive for recycling of wastes. On the other hand this practice has economical side of advantage.

The research assessed out whether the respondents reuse solid waste or not. The fact is that the majority of the respondents, $86.7 \%$ don't reuse household wastes. This could be the indicator of the higher proportion of the solid waste generated from the households ends up at the municipality waste disposal sites or other unsafe ways of waste disposal mentioned earlier. With this respect an intact effort is required from all stake holders. Only $13.3 \%$ of the respondents reuse household wastes. Anyhow this result is higher than that found in Mogadishu, Somalia which was only $6.5 \%$. [13]

Analysis of means of waste collection in each district indicates that $41.7 \%$ use donkey driven carts, $34 \%$ of respondents dispose their waste by their hands and $24.3 \%$ use hand driven carts. This result is quit close to the result found at Mogadishu city, Somalia, where the respondents used donkey driven carts and by hand; $46 \%$ and $34.6 \%$, respectively. This make similar with that of Mogadishu city households used carts to haul solid waste. [13] Using those methods is not safe enough to keep the sanitation of the town because there may be droppings of waste across the roads as it is hauled to the final disposal site.

\section{Conclusion and Recommendation}

This study revealed that household management of waste in the community of Yirgalem town is poor in terms of their liquid waste management. More than seventy six percent of the households flush away their waste water indiscriminately. But it is moderately good in terms of their solid waste management because of very high proportion of the households had temporary storage for solid waste. Majority of the households had latrines, and almost $83.7 \%$ of the available latrines were traditional pits in poor sanitary conditions due to the presence of feces in the wall of latrine.

This study also revealed that households' management of solid waste in the community is moderately good. Even if majority of the households have no cover for their storage of waste and do not apply onsite separation of waste before storage, majority of the households have a temporary prepared for storage of waste rather than disposing it indiscriminately. This makes the household management of solid waste in Yirgalem town is moderately good. Participation in turn is related to various factors, among which are fears for diseases associated with poor management of solid waste disposal, which respondents believe mostly affect small children.
According to the information obtained from the respondents, although the highest proportion of households use municipality service for waste disposal, sometimes the absence of donkey driven carts leads households to dump solid waste outside their houses or burn it within the compound or deposit it in illegal dumping sites, most of which are located near to houses and pose major health risks. According to the situation of the final disposal site of the municipality it is very risky to the surrounding community because there is nothing done to improve it.

\section{Competing Interests}

The authors declare that they have no competing interests.

\section{Authors' Contributions}

BT-performed data collections, analyzed the data and wrote the manuscript. All authors read and approved the final manuscript.

\section{Acknowledgements}

I would like to acknowledge the university of Hawassa and CBE office for financial and technical support. I also would like to express my heartfelt thanks to mine advisor Beekam Kebede (MSc in Environmental health and technology) for his genuine and valuable comment given for me.

\section{References}

[1] William PC, Mary AC, Barbara S. Waste management. Environmental Sciences: A global concern. McGraw-Hill publisher, New York. 2005; 3-44.

[2] Akankeng E. (2003) Globalization, urbanization and municipal solid waste management in Africa.

[3] Enete, I. (2010) Potential Impacts of Climate Change on Solid Waste Management in Nigerian. Journal of Sustainable Development in Africa, 12, 101-103.

[4] Adeboye, K. (2001,) Timeline of Change in Waste Management Practices. The Environmentalist, 20, 110-112.

[5] Hutton G and Bartram J. Global cost of attaining the Millennium Development Goal for water supply and sanitation. Bulletin of the World Health Organization. 2008: 86 (1): $1-80$.

[6] World Bank (2004,) Regional Guidelines on Integrated Solid Waste Management, Prepared by an International Consortium of Expert Consultants.

[7] Taylor R. (2006) Waste Disposal and Landfill: Potential Hazards and Information Needs. Protecting Groundwater for Health: Managing the Quality of Drinking Water Resources. WHO, World Health Organization (Eds.), 339-360.

[8] Sharama BK. Solid, toxic, and hazardous waste. Environmental chemistry. Goal publishing, India. 2005 466.; 455-466. 
[9] Bizatu M. and Negga, B. (2010) Community based assessment on household management of waste and hygiene practices in Kersa Woreda, Ethiopia. Ethiopian J. Health Dev, 2, 103-109.

[10] Legesse W, Haile Mariam D, Kloos H. Water supply and sanitation. In; Berhane Y, Haile Mariam D, Kloos H (editors). Epidemiology and Ecology of health and disease in Ethiopia. Shama Books. 2006 edition; 129-146.

[11] World Health Organization. Combating water borne disease at the household level: International network to promote household water treatment and safe storage. Geneva, Switzerland. WHO, 1993.

[12] Fetene G and Donald R. A Sanitation Assessment of a rural Ethiopian village. Texas Journal of Rural Realth.2003; 21 (4): 18-23.

[13] Peter M. Assessment of solid waste management system among residents of Mogadishu, Somalia, Ethiopia. 2012; 15 (4): 21-23.
[14] Mohammed Z. Domestic waste disposal practice assessment among residents of Assendabo town, Southern Ethiopia. 2002; $21(5): 15-17$.

[15] Rabie T and Curtis V. Hand washing and risk of respiratory infections: a quantitative systematic review. Tropical medicine and international health. 2006; 011 (3): 258-67.

[16] Cairncross S, Hunt S, Bostoen C, Boisson K, Curtis V, Fung I and Schmidt WP. Water, sanitation and hygiene for the prevention of diarrhoea. International Journal of Epidemiology. 2010; 39: (1): 193-205.

[17] Jerry A. Waste water treatment and disposal. Basic environmental technology, water supply, waste management and pollution control, 3rd Edition, New Jersey. 2000; 227-71.

[18] Dereje Tadesse (2001) Financing urban infrastructures and services in Ethiopia: The case of Solid waste Management in Adama. School of Graduate Studies, Addis Ababa University. 